\title{
Effect of neoadjuvant chemotherapy on low-density lipoprotein (LDL) receptor and LDL receptor-related protein 1 (LRP-1) receptor in locally advanced breast cancer
}

\author{
L.A. Pires ${ }^{1,2}$, R. Hegg ${ }^{2}$, F.R. Freitas ${ }^{1}$, E.R. Tavares ${ }^{1}$, C.P. Almeida ${ }^{1}$, \\ E.C. Baracat ${ }^{2}$ and R.C. Maranhão $0^{1,3}$ \\ ${ }^{1}$ Laboratório de Metabolismo de Lípides, Instituto do Coração, Faculdade de Medicina, \\ Hospital das Clínicas, Universidade de São Paulo, São Paulo, SP, Brasil \\ ${ }^{2}$ Departamento de Ginecologia, Faculdade de Medicina, Hospital das Clínicas, \\ Universidade de São Paulo, São Paulo, SP, Brasil \\ ${ }^{3}$ Faculdade de Ciências Farmacêuticas, Universidade de São Paulo, São Paulo, SP, Brasil
}

\begin{abstract}
Low-density lipoprotein (LDL) receptors are overexpressed in most neoplastic cell lines and provide a mechanism for the internalization and concentration of drug-laden nanoemulsions that bind to these receptors. The aim of the present study was to determine whether the administration of standard chemotherapeutic schemes can alter the expression of LDL and LDL receptor-related protein 1 (LRP-1) receptors in breast carcinoma. Fragments of tumoral and normal breast tissue from 16 consecutive volunteer women with breast cancer in stage II or III were obtained from biopsies before the beginning of neoadjuvant chemotherapy and after chemotherapy, from fragments excised during mastectomy. Tissues were analyzed by immunohistochemistry for both receptors. Because complete response to treatment was achieved in 4 patients, only the tumors from 12 were analyzed. Before chemotherapy, there was overexpression of LDL receptor in the tumoral tissue compared to normal breast tissue in 8 of these patients. LRP-1 receptor overexpression was observed in tumors of 4 patients. After chemotherapy, expression of both receptors decreased in the tumors of 6 patients, increased in 4 and was unchanged in 2. Nonetheless, even when chemotherapy reduced receptors expression, the expression was still above normal. The fact that chemotherapy does not impair LDL receptors expression supports the use of drug carrier systems that target neoplastic cells by the LDL receptor endocytic pathway in patients on conventional chemotherapy.
\end{abstract}

Key words: Breast cancer; Lipoproteins; LDL receptor; LRP-1 receptor; Chemotherapy; Nanoemulsion; Drug delivery

\section{Introduction}

Low-density lipoprotein (LDL) is removed from the circulation by specialized membrane receptors that internalize the lipoprotein particles into cells. LDL receptors recognize apolipoprotein (Apo) B, which is the only Apo present in the LDL structure. LDL receptors are grouped in coated pits, depressions on the cell membrane that are reinforced by a clathrin cover (1). After binding of LDL receptors, clathrin vesicles are formed, containing the LDL particles and the receptors. The vesicles fuse with lysosomes and the $\mathrm{pH}$ in the interior of receptosomes falls. The vesicles dehydrate and disrupt and the lipid and degraded protein content is dispersed in the cytosol. LDL receptors recirculate back to coated pits in the plasma membrane (1). LDL receptors recognize not only $A$ po $B$ but also Apo $E$, which is not present in LDL but is present in other lipoproteins such as very-lowdensity lipoprotein (VLDL) or chylomicron remnants.

LDL receptors are up-regulated in many neoplastic cell lines (2-4) and this phenomenon may be of prognostic significance (5). Most importantly, the LDL receptor endocytic pathway can be used as a gate to deliver anticancer drugs to tumor tissues $(6,7)$. This can be performed by including drugs in lipoproteins that, after injection into the circulation, concentrate in the cells with LDL receptor upregulation. In previous studies, we showed that non-protein

Correspondence: R.C. Maranhão, Instituto do Coração (InCor), Hospital das Clínicas, FM-USP, Av. Dr. Eneas C. Aguiar, 44, 05403-000 São Paulo, SP, Brasil. Fax: +55-11-3069-5574. E-mail: ramarans@usp.br

Received August 6, 2011. Accepted March 26, 2012. Available online May 4, 2012. Published June 4, 2012. 
nanoemulsions that are artificially prepared and resemble the lipid structure of LDL can also be directed at tumors by the LDL receptor pathway (8). After injection into the blood stream, these nanoemulsions acquire Apo $E$ from the native lipoproteins and bind to the LDL receptors through Apo E (8).

Other studies have shown that another receptor that can take up lipoproteins, the LDL receptor-related protein (LRP) receptor can be also overexpressed in neoplastic cells (9). LRP receptor is a member of the LDL receptor family but recognizes a broader spectrum of ligands and has a wide spectrum of biological functions $(10,11)$. Initially, LRP was thought to primarily serve as a lipoprotein receptor due to its resemblance to LDL receptors. In addition, LRP binds the blood proteins $\alpha 2$-macroglobulin and tissue plasminogen activator and its inhibitors. The LRP receptor recognizes Apo $E$ of lipoproteins and binds remnants produced by the digestion of the triacylglycerol of chylomicrons and VLDL by lipoprotein lipase $(12,13)$. The LRP receptor is abundant in the cell membranes of the liver, brain and placenta (14).

Lipoprotein receptors up-regulation in neoplastic cells may be related to the increased need by the cell to internalize lipids such as cholesterol and phospholipids to build new membranes required by the accelerated mitosis rates (15). We have shown that, after injection into breast cancer patients who were scheduled to be submitted to mastectomy in the ensuing $24 \mathrm{~h}$, nanoemulsions that pick up Apo $E$ concentrated in the excised tumors several-fold more than in normal mammary tissue (16-18).

For a large number of patients with breast cancer, chemotherapy is the first choice of treatment. However, the toxicity of the chemotherapeutic agents and the low therapeutic index are strong limitations of successful treatment (19). Drug targeting may offer an interesting strategy to improve the efficiency of chemotherapy $(20,21)$. It has been reported that association with a nanoemulsion dramatically reduces the toxicity of several chemotherapeutic agents, as shown in clinical trials enrolling patients with breast cancers and other solid or hematologic neoplasias $(22,23)$. As overexpression of lipoprotein receptors is a remarkably differential phenomenon in neoplastic cells, characterization of these receptors in tumors should be extensively documented to favor the use of these new strategies.

The objective of the present study was to investigate whether chemotherapy alters the expression of LDL and LRP receptors. This is a practical question regarding whether the tumors of patients who were already being treated with chemotherapeutic agents could still show receptor overexpression. If so, the introduction of drugs carried in LDL receptor binding nanoemulsions may be feasible. To address this issue, fragments of breast tumors and normal tissues excised in biopsies and during mastectomy were studied before and after neoadjuvant chemotherapy and the extent of the expression of LDL and LRP-1 receptors was determined by immunohistochemistry.

\section{Material and Methods}

\section{Subjects}

Sixteen consecutive volunteer women with breast cancer in stage II or III who were not candidates for conservative surgery and with an indication of neoadjuvant chemotherapy participated in the study. The patients were selected in the Oncology Section of the Women's Health Hospital (São Paulo, Brazil). The diagnosis was based on a previously obtained biopsy. The patients had adequate bone marrow function, with absolute granulocyte count $\geq 1.5 \times 10^{9} / \mathrm{L}$, platelet count $\geq 100 \times 10^{9} / \mathrm{L}$, and hemoglobin $\geq 10 \mathrm{~g} \%$. Hepatic and renal functions were also normal. Patients had no previous breast cancer treatment and had performance status $\leq 2$, the scale commonly used for appraisal of an individual's ability to manage activities of daily living, created by the USA Eastern Cooperative Oncology Group (ECOG)/World Health Organization (WHO) (24).

Table 1 shows individual data such as patient age, histological diagnosis, grade of nuclear differentiation, clinical and pathological staging, and response to neoadjuvant chemotherapy. All breast cancer cases were staged clinically and pathologically at diagnosis from 0 to 4 depending on the combination of TNM category ( $\mathrm{T}=$ tumor size, $\mathrm{N}=$ amount of regional lymph node involvement, $M=$ metastases). Grade of nuclear differentiation refers to the size and shape of the nucleus in tumor cells and the percentage of tumor cells that are dividing, described by four degrees of severity. These stagings were defined by the $\mathrm{NCl}-\mathrm{NIH}$ (National Cancer Institute-National Institute of Health), USA, and revised by the American Joint Committee on Cancer Staging System for Breast Cancer (AJCC) (25).

Exclusion criteria were inflammatory carcinoma, metastatic disease, multifocal disease, bilateral tumor, cardiac arrhythmia grade two or more, active infection, presence of severe psychiatric disease, or second malignancy (except for in situ carcinoma of the cervix or adequately treated basal cell carcinoma of the skin), and pregnant or nursing patients.

The immunohistochemical features and diagnosis of pathological staging were performed at the Department of Pathology of the Women's Health Hospital.

The study was approved by the Ethics Committee of the Women's Health Hospital (Protocol No. 0296/09) and all participants gave written informed consent.

\section{Determination of serum lipids}

Blood samples for the determination of laboratory parameters were collected after a 12-h fast on the same day of the biopsy. Commercial enzymatic colorimetric methods were used for the determination of total cholesterol, triacylglycerides and HDL-C (Labtest, Brazil). LDL-C was calculated according to the Friedewald formula (26). 


\section{Immunohistochemical analysis}

Five-micron thick sections of formalin-fixed paraffinembedded tissue were routinely processed. For immunohistochemical analysis, the anti-LDLR rabbit antimouse polyclonal antibody against synthetic peptide from murine LDL receptor amino acids 499-511 (SVADTKGVKRRTL; LifeSpan Biosciences Inc., USA) and the anti-LRP antimouse monoclonal antibody against the 5A6 clone (Calbiochem, Germany) were used in this study. Specificity of the antibody was tested in mouse liver fragments, which is a standard procedure, since the liver expresses the highest amount of LRP (Figure 1).

For immunostaining for LRP-1, antigen retrieval was

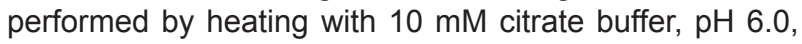
for $30 \mathrm{~min}$ and cooling for $5 \mathrm{~min}$ at room temperature. For immunostaining for LDLR, antigen retrieval was not necessary. Endogenous peroxidase activity was blocked by incubation in 3\% hydrogen peroxide. Briefly, each tissue section was incubated in fetal calf serum for $1 \mathrm{~h}$ at $42^{\circ} \mathrm{C}$. The slides were then incubated overnight at $4^{\circ} \mathrm{C}$ with a 1:50 dilution of anti-LDLR antibody or with a 1:400 dilution of anti-LRP antibody. Next, the sections were incubated for $30 \mathrm{~min}$ at room temperature with a SuperPicture Polymer Detection System (Invitrogen Co., USA). The sections were incubated with a 3,3'-diamino-benzidine (DAB) chromogen system (Dako America Inc., USA) for $1.5 \mathrm{~min}$ at room temperature and then counterstained with hematoxylin. Between incubations, the slides were rinsed three times for 5 min with PBS. In the negative control experiment, both primary antibodies were replaced with $1 \%$ bovine serum albumin (Figure 1).

For quantitative image analysis of immunostaining for LDL and LRP-1 receptors, the color detection threshold was chosen for the DAB chromogen in tissue sections. The settings for chromogen staining were optimized so that all cells that were identified as labeled above background by visual inspection were also scored by the image analysis software. Multiple fields (2-6 depending on section size) from each section were captured at 200X magnification by means of the Image Analysis System Quantimet 500+ (Leica Cambridge Ltda., UK) and the area was calculated as percentage of the area immunostained in each field. The mean for each patient was calculated based on all fields measured in each section.

\section{Results}

Table 1 shows the clinical staging, as established before the beginning of chemotherapy, and the pathological staging established by the examination of the tissue fragments excised during surgery. Among 16 subjects, only 4 presented complete response to chemotherapy.

The quantitative analysis of the estrogen and progesterone receptors and human epidermal growth factor receptortype 2 (HER-2) status is shown in Table 2. Eight patients presented positivity for hormonal receptors, 3 presented HER-2 hyperexpression, and 5 were characterized as triple negative (estrogen receptor (ER), progesterone receptor (PgR), and HER-2 negative).

Table 3 shows the chemotherapy regimen used in each subject with the number of cycles performed. The patients received 4 to 11 chemotherapy cycles.

Regarding the plasma lipid profile before the beginning of chemotherapy, total cholesterol was $231 \pm 68$ (mean \pm standard deviation), LDL-C was in $141 \pm 65$, HDL-C was $63 \pm 20$, and triglycerides were $136 \pm 65 \mathrm{mg} / \mathrm{dL}$.

\section{Immunohistochemistry of LDL receptor}

Table 4 shows the expression of LDL receptor in normal tissue and in tumor tissue before and after chemotherapy. Because of the absence of tumor in the surgical fragments, patients who presented a complete response to chemotherapy were excluded from this analysis. Eight of 11 patients evaluated presented higher LDL receptor expression in tumor tissue than in normal tissue. For 3 patients, however, LDL receptor expression was lower in the tumor than in the normal tissue.

Chemotherapy reduced the expression of LDL receptor in the tumor tissue of 6 patients. However, in 4 patients the expression of the LDL receptor increased and in 2 it was unchanged.

Among the 8 patients who presented tumors with high LDL receptor expression before chemotherapy, 2 showed a further increase in LDL receptor expression, in 1 the receptor expression was unchanged, whereas in 5 patients the receptor expression was reduced after chemotherapy. In 3 of the 5 patients the receptor expression of tumor tissue was still higher than that of normal tissue.

Among the 3 patients who showed LDL receptor expression in the tumor before chemotherapy, chemotherapy elicited different responses: in 1 the LDL receptor expression increased, in 1 it decreased, and in the other it was unchanged.

\section{Immunohistochemistry of LRP-1 receptor}

Table 5 presents LRP-1 receptor expression in normal tissue compared to tumor tissue before and after chemotherapy. Among 12 patients evaluated, receptor expression in tumor tissue was increased in 4 and decreased in 3 compared to the corresponding normal tissue. In 5 the expression of LRP-1 receptor was the same in tumors and in normal tissues.

After chemotherapy, the expression of the LRP-1 receptor was reduced in the tumors of 6 patients, increased in 4 , and unchanged in 2.

Among the 4 patients who showed tumors with high LRP-1 receptor expression before chemotherapy, the receptor expression was reduced after chemotherapy in 2 , whereas in 2 there was a further increase in the LDL receptor expression.

Among the 3 patients who showed tumors with low 


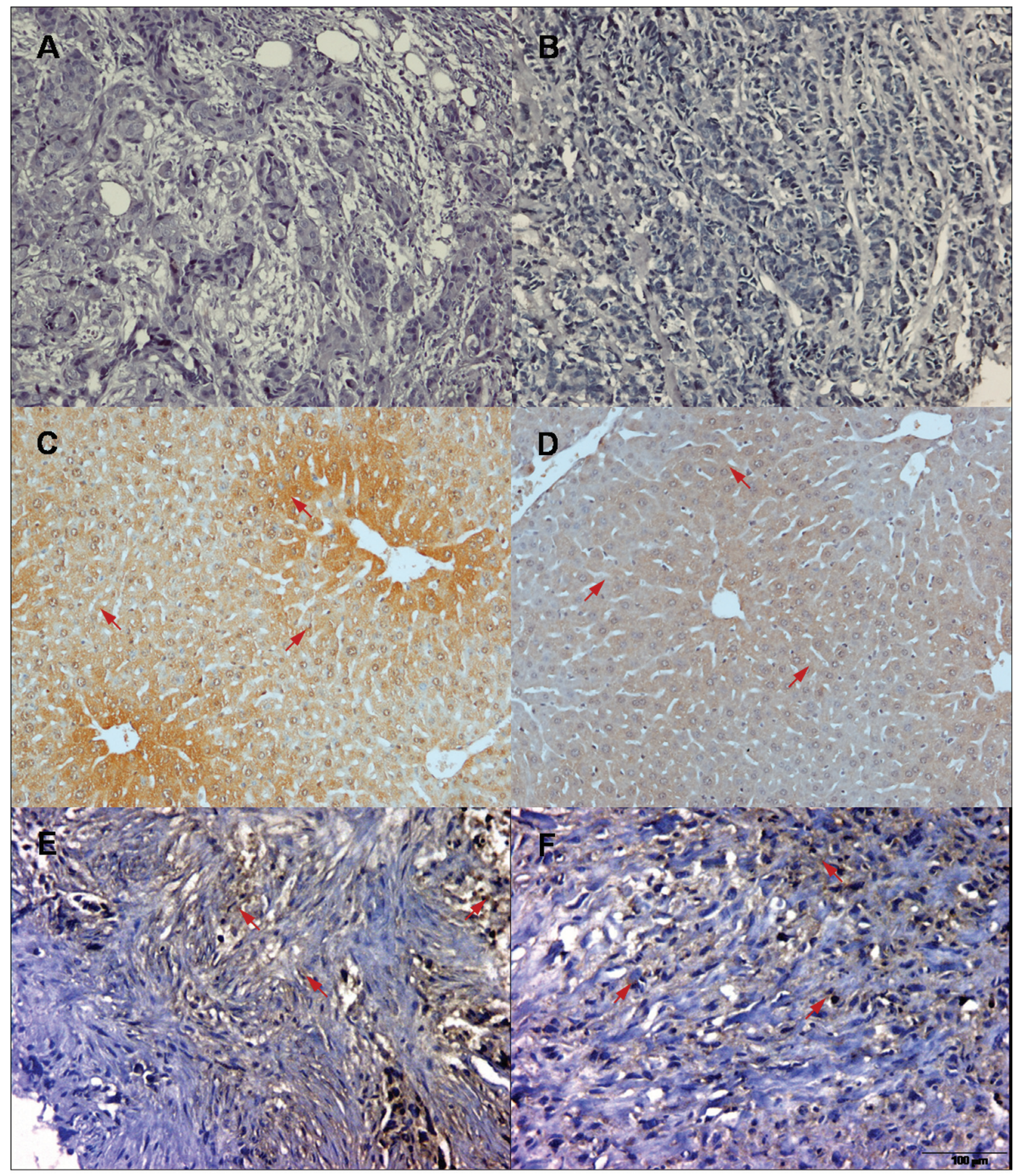

Figure 1. Photomicrograph of human breast tumor tissue and mouse liver tissue, indicating the negative and positive controls of the immunohistochemistry protocol for low-density lipoprotein (LDL) receptor $(A, C$ and $E)$ and LDL receptor-related protein 1 receptor $(B$, $D$ and $F$ ). $A$ and $B$, Negative control, performed in human breast tissue, in which the primary antibody was replaced with bovine serum albumin. $C$ and $D$, Positive control, performed in mouse liver, which shows the highest protein expression of lipoprotein receptors. $E$ and $F$, Immunohistochemistry performed in human breast tumor tissue. Brown staining (arrows) indicates the expression of lipoprotein receptors immunostained by DAB chromogen. 
Table 1. Age, histological diagnosis, grade of nuclear differentiation, clinical and pathological staging (CS and PS), and response to neoadjuvant chemotherapy of the patients in the present study.

\begin{tabular}{|c|c|c|c|c|c|c|c|c|c|c|}
\hline \multirow[t]{2}{*}{ Patients } & \multirow[t]{2}{*}{$\begin{array}{c}\text { Age } \\
\text { (years) }\end{array}$} & \multirow[t]{2}{*}{$\begin{array}{c}\text { Histological } \\
\text { diagnosis }\end{array}$} & \multirow[t]{2}{*}{ G } & \multicolumn{3}{|c|}{ Clinical staging } & \multicolumn{3}{|c|}{$\begin{array}{l}\text { Pathological } \\
\text { staging }\end{array}$} & \multirow[t]{2}{*}{ Response } \\
\hline & & & & $\mathrm{T}$ & $\mathrm{N}$ & CS & $\mathrm{T}$ & $\mathrm{N}$ & PS & \\
\hline 1 & 58 & IDC & 2 & $4 b$ & 1 & IIIB & $4 b$ & $1 \mathrm{a}$ & IIIB & ICR \\
\hline 2 & 53 & ILC & 1 & 3 & 1 & IIIA & 4 & 1 & IIIB & ICR \\
\hline 3 & 53 & IDC & 2 & 3 & 0 & IIB & $4 b$ & $1 \mathrm{a}$ & IIIB & ICR \\
\hline 4 & 34 & IDC & 2 & 3 & 2 & IIIA & 4 & $3 a$ & IIIC & ICR \\
\hline 5 & 64 & IDC & 2 & 2 & 2 & IIIA & 2 & $2 a$ & IIIA & ICR \\
\hline 6 & 60 & IDC & 2 & $4 b$ & 1 & IIIB & $4 b$ & 3 & IIIC & ICR \\
\hline 7 & 40 & IDC & 2 & $4 b$ & 1 & IIIB & $4 b$ & 2 & IIIB & ICR \\
\hline 8 & 48 & IDC & 2 & 3 & 2 & IIIA & 4 & 2 & IIIB & ICR \\
\hline 9 & 49 & IDC & 1 & 3 & 2 & IIIA & 2 & 3 & IIIC & ICR \\
\hline 10 & 63 & IDC & 3 & $4 b$ & 2 & IIIB & 4 & 0 & IIIB & ICR \\
\hline 11 & 53 & IDC & 3 & 3 & 1 & IIIA & $1 \mathrm{c}$ & $1 \mathrm{a}$ & $\| A$ & ICR \\
\hline 12 & 41 & IDC & 2 & 3 & 1 & IIIA & 2 & 1 & IIB & ICR \\
\hline 13 & 37 & IDC & 2 & 3 & 2 & IIIB & 0 & 0 & 0 & CR \\
\hline 14 & 51 & IDC & 2 & 3 & 3 & IIIC & 0 & 0 & 0 & CR \\
\hline 15 & 46 & IDC & 2 & 3 & 2 & IIIB & 0 & 0 & 0 & CR \\
\hline 16 & 48 & IDC & 2 & 2 & 1 & IIB & 0 & 0 & 0 & CR \\
\hline
\end{tabular}

IDC = invasive ductal carcinoma; ILC = invasive lobular carcinoma; $\mathrm{G}=$ grade of nuclear differentiation; $\mathrm{T}$ and $\mathrm{N}=$ tumor and node of the TNM staging system; ICR = incomplete response; $\mathrm{CR}=$ complete response.

Table 2. Quantitative analysis of the estrogen and progesterone receptors and HER-2 status before chemotherapy.

\begin{tabular}{cccc}
\hline Patients & $\begin{array}{c}\text { Estrogen } \\
\text { receptor }\end{array}$ & $\begin{array}{c}\text { Progesterone } \\
\text { receptor }\end{array}$ & Cerb-B2 \\
\hline 1 & $>75 \%$ positive & $25 \%$ positive & Negative \\
2 & $75 \%$ positive & Negative & Negative \\
3 & Negative & Negative & $3+/ 3+$ \\
4 & $50-75 \%$ positive & Negative & Negative \\
5 & $25-50 \%$ positive & Negative & $2+/ 3+$ \\
6 & $25 \%$ positive & Negative & Negative \\
7 & $10-25 \%$ positive & Negative & Negative \\
8 & $50 \%$ positive & $<25 \%$ positive & Negative \\
9 & Negative & Negative & $3+/ 3+$ \\
10 & Negative & Negative & Negative \\
11 & Negative & Negative & Negative \\
12 & Negative & Negative & Negative \\
13 & Negative & Negative & Negative \\
14 & Negative & Negative & $3+/ 3+$ \\
15 & $>75 \%$ positive & Negative & $2+/ 3+$ \\
16 & Negative & Negative & Negative \\
\hline
\end{tabular}

Cerb-B2 = human epidermal growth factor receptor $2 ; 2+/ 3+=$ doubtful result; $3+/ 3+=$ positive result for Cerb-B2 status.
Table 3. Chemotherapy regimen and cycles performed.

\begin{tabular}{ccc}
\hline Patients & $\begin{array}{c}\text { Chemotherapy } \\
\text { regimen }\end{array}$ & $\begin{array}{c}\text { Number of } \\
\text { chemotherapy cycles }\end{array}$ \\
\hline 1 & AC & 4 \\
2 & AC & 4 \\
3 & AC + DCT & $4+4=8$ \\
4 & AC & 4 \\
5 & GCT/DDP & 6 \\
6 & ADM/DDP + GCT/DDP & $5+6=11$ \\
7 & ADM/DDP & 6 \\
8 & PCT/ADM & 8 \\
9 & PCT/ADM & 6 \\
10 & GCT/DDP & 6 \\
11 & AC & 4 \\
12 & GCT/DDP & 6 \\
13 & ADM/DDP & 6 \\
14 & PCT/GCT & 8 \\
15 & PCT/GCT & 6 \\
16 & ADM/DDP & 6 \\
\hline
\end{tabular}

$\mathrm{AC}=$ doxorubicin + cyclophosphamide; $\mathrm{DCT}=$ docetaxel; $\mathrm{GCT} /$ $\mathrm{DDP}=$ gemcitabine + cisplatin; $\mathrm{ADM} / \mathrm{DDP}=$ doxorubicin + cisplatin; PCT/ADM = paclitaxel + doxorubicin; PCT/GCT = paclitaxel + gemcitabine. 
LRP-1 receptor expression before chemotherapy, the receptor expression was reduced after chemotherapy in 2, whereas it was further increased in one.

Among the 5 patients who showed unchanged LRP-1 receptor expression in the tumor before chemotherapy, treatment elicited different responses: in 1 the LRP-1 receptor expression increased, in 2 it decreased, and in 3 it was unchanged.

No correlations were found between the expression of both LDL and LRP receptors and PgR or ER status (Pearson's correlation).

\section{Discussion}

In this study, 8 of 11 patients showed high LDL receptor expression in tumor tissue before chemotherapy compared to the matched normal breast tissue. In our previous studies, without exception, in all 35 patients injected with the radioactive nanoemulsion the concentration of the tracer was greater in the breast tumor than in the normal tissue. This observation was made by either nuclear medicine imaging using ${ }^{99} \mathrm{Tc}$-labeled nanoemulsions or radioactive measurement of the excised tumors after injection of nanoemulsions labeled with tritium before mastectomy $(16-18,27)$. The fact that 3 of the 11 patients in this study did not show LDL receptor overexpression does not imply that increased uptake of lipoproteins would not occur in these patients. Although increased uptake of the lipoprotein occurs chiefly by increasing the number of lipoprotein receptors on the cell surface, other mechanisms can also be at work to increase uptake without an increase in receptor number. Acceleration of receptor recycling can be one of the mechanisms whereby increase in uptake could occur, since speeding up receptor disposal leads to enhancement of receptor function (23).

On the other hand, in those tumors in which LDL receptor expression was higher in tumor tissue than in the corresponding normal breast tissue, there was a wide variation in the expression data. This variation ranged from 1.4-fold (patient number 8) to 13-fold (patient number 3) that of normal tissue. A wide variation was also observed in our previous studies $(16,17,27,28)$ regarding the nanoemulsion tissue uptake, which was greater in the tumor than in the normal tissue by 1.4- to 8.8-fold. Incidentally, the pattern of wide variation in the increase of LDL receptor expression has been reported in several studies since the seminal study by $\mathrm{Ho}$ et al. (2): in acute myelocytic leukemia cells, LDL receptor overexpression varied from 3- to 100-fold. It is noteworthy that in normal tissues the LDL receptors also showed a wide variation of expression among patients. This certainly reflects changes in intracellular cholesterol saturation and cellular demands of lipids.

The effects of chemotherapy on the tumoral expression of LDL receptors were very heterogeneous, so that the interpretation of these data is difficult. Assuming that
Table 4. LDL receptor expression in normal and tumor tissue pre- and post-chemotherapy determined by immunohistochemistry (\%).

\begin{tabular}{rccc}
\hline Patients & $\begin{array}{c}\text { Normal } \\
\text { tissue }\end{array}$ & $\begin{array}{c}\text { Tumor } \\
\text { pre-chemotherapy }\end{array}$ & $\begin{array}{c}\text { Tumor } \\
\text { post-chemotherapy }\end{array}$ \\
\hline 1 & 14.9 & 9.0 & 8.5 \\
2 & 0.5 & 6.0 & 10.3 \\
3 & 13.5 & 1.9 & 2.4 \\
4 & 18.2 & 6.4 & 2.0 \\
5 & 10.0 & 22.3 & 2.1 \\
6 & - & 15.5 & 50.7 \\
7 & 2.5 & 13.7 & 15.9 \\
8 & 16.6 & 23.0 & 4.0 \\
9 & 4.1 & 7.0 & 11.4 \\
10 & 7.0 & 15.8 & 12.0 \\
11 & 2.4 & 18.6 & 5.8 \\
12 & 3.6 & 33.7 & 14.3 \\
\hline
\end{tabular}

Data are reported as percentage of cells positive to the LDLR antibody.

Table 5. LRP-1 receptor expression in normal and tumor tissue pre- and post-chemotherapy determined by immunohistochemistry $(\%)$.

\begin{tabular}{cccc}
\hline Patients & $\begin{array}{c}\text { Normal } \\
\text { tissue }\end{array}$ & $\begin{array}{c}\text { Tumor } \\
\text { pre-chemotherapy }\end{array}$ & $\begin{array}{c}\text { Tumor } \\
\text { post-chemotherapy }\end{array}$ \\
\hline 1 & 3.7 & 4.2 & 0.3 \\
2 & 8.1 & 5.6 & 1.0 \\
3 & 4.7 & 6.2 & 11.3 \\
4 & 20.0 & 3.2 & 1.6 \\
5 & 2.5 & 4.0 & 1.4 \\
6 & 4.4 & 4.7 & 12.5 \\
7 & 2.4 & 0.3 & 0.5 \\
8 & 14.0 & 13.4 & 3.5 \\
9 & 5.5 & 7.2 & 4.3 \\
10 & 1.4 & 3.3 & 5.4 \\
11 & 4.7 & 5.1 & 5.0 \\
12 & 11.0 & 8.5 & 9.1 \\
\hline
\end{tabular}

Data are reported as percentage of cells positive to the LRP-1 antibody.

overexpression of receptors is caused by the accelerated lipid-dependent membrane synthesis, by inhibiting mitosis it should be expected that the receptor expression would decrease. Indeed, the expected effect was observed in 6 of the patients, but in 4 patients the post-chemotherapy expression values were higher than the pre-chemotherapy ones and in 2 the expression was unchanged. This suggests that the relationship between receptor expression and mitosis is not so straightforward or, eventually, these findings could also be related to drug resistance. 
Regarding the LRP receptor, by comparing prechemotherapy values of tumors with those of matched normal breast tissues, the expected pattern of increased expression in tumors was unclear: whereas higher tumor values were found in 4 patients, in 3 they were lower, and in 5 they were equal. In contrast to the consistent reports of LDL receptor overexpression in most cancers, with few exceptions such as lymphocytic acute leukemia, the issue of whether or not there is simultaneous LRP receptor overexpression has been much less explored, with rather controversial results $(9,29)$. The response to chemotherapy of LRP receptor expression was somewhat similar to that found in LDL receptor, with the expected decrease in expression occurring in the tumors of 6 patients, an increase in 4 and unchanged values in 2 patients.

Because receptor expression is not the sole determinant of receptor-mediated endocytosis, studies on the uptake of lipoproteins or artificial nanoemulsions should be performed in patients to confirm the influence of chemotherapy on tissue uptake.

Most of the breast tumors studied here were the invasive ductal carcinoma type, which is the most common, accounting for approximately $85 \%$ of the total breast cancer incidence. Histology showed lobular invasion in only one case. The data obtained here about the expression of lipoprotein receptors in this neoplasia are important in view of the challenging possibilities of using the LDL receptor endocytic pathway to concentrate anticancer drugs at their site of action. Our group has already shown that the use as drug vehicles of lipid nanoemulsions that bind to these receptors may provide a strong reduction of side effects. This was demonstrated at the clinical trial level with different chemotherapeutic agents such as carmustine (22), etoposide $(28,30)$ and paclitaxel $(17,31)$ and in patients with different solid and hematologic cancers. The animal studies showed that the pharmacologic action of nanoemulsionassociated drugs was not reduced. The possibility tested here was whether conventional chemotherapy may diminish the receptor expression so that a subsequent introduction of nanoemulsion-based chemotherapy would be less efficient. Our results show that, fortunately, a reduction of receptor expression is not the post-chemotherapy pattern.

The fact that the PgR or ER status did not correlate with

\section{References}

1. Goldstein JL, Anderson RG, Brown MS. Coated pits, coated vesicles, and receptor-mediated endocytosis. Nature 1979; 279: 679-685.

2. Ho YK, Smith RG, Brown MS, Goldstein JL. Low-density lipoprotein (LDL) receptor activity in human acute myelogenous leukemia cells. Blood 1978; 52: 1099-1114.

3. Gal D, MacDonald PC, Porter JC, Simpson ER. Cholesterol metabolism in cancer cells in monolayer culture. III. Low-density lipoprotein metabolism. Int J Cancer 1981; 28: 315-319. the expression of LDL or LRP receptors is irrelevant because the features that are critical for hormone therapy are not related to the indication or outcome of chemotherapy.

The liver is the major site of lipoprotein and nanoemulsion uptake in the body and consequently of the drugs carried in nanoemulsions. Nonetheless, in animals implanted with B16 melanoma or Walker tumor, we showed that different drugs carried in nanoemulsions that bind to LDL receptors, such as carmustine (32), etoposide (33), paclitaxel (34) or daunorubicin (35) were more efficient in inhibiting tumor growth than the commercial preparations of these drugs. In multiple myeloma patients, the use of carmustine associated with the nanoemulsion resulted in amelioration of both clinical and laboratorial disease parameters (36). In addition, we showed that the use of nanoemulsions markedly reduced drug toxicity in animal experiments $(22,32-35)$ and in clinical trials $(16-18,23,28,30,31,36)$.

Immunohistochemistry has been widely used to assess the presence of receptors in neoplastic breast tissues. Since the neoplastic disease processes do not produce defective lipoprotein receptors, it is expected that the receptor amounts detected by immunohistochemistry, with a high degree of specificity, are not dysfunctional. Determination of the uptake of the radioactively labeled nanoemulsion by tumor tissue, as performed in our previous studies (17), is the ultimate measurement of receptor function but does not discriminate among the different receptors involved in the uptake, such as the LDL receptor, LRP receptor or scavenger receptor class b member 1 (SRB1).

The novel findings described here regarding the status of lipoprotein receptors after chemotherapy could help to establish basic cellular mechanisms that may contribute to the design of future clinical assays dealing with nanotechnology treatment approaches.

\section{Acknowledgments}

The authors are grateful to Departamento de Patologia, Centro de Referência da Saúde da Mulher (São Paulo, SP, Brazil) for establishing the pathological status of the patients. R.C. Maranhão is the recipient of a research grant from CNPq. Research supported by FAPESP.

4. Vitols S, Peterson C, Larsson O, Holm P, Aberg B. Elevated uptake of low density lipoproteins by human lung cancer tissue in vivo. Cancer Res 1992; 52: 6244-6247.

5. Rudling MJ, Stahle L, Peterson CO, Skoog L. Content of low density lipoprotein receptors in breast cancer tissue related to survival of patients. Br Med J 1986; 292: 580-582.

6. Rudling MJ, Collins VP, Peterson CO. Delivery of aclacinomycin A to human glioma cells in vitro by the low-density lipoprotein pathway. Cancer Res 1983; 43: 4600-4605. 
7. Lundberg B. Preparation of drug-low density lipoprotein complexes for delivery of antitumoral drugs via the low density lipoprotein pathway. Cancer Res 1987; 47: 4105-4108.

8. Maranhão RC, Cesar TB, Pedroso-Mariani SR, Hirata MH, Mesquita $\mathrm{CH}$. Metabolic behavior in rats of a nonprotein microemulsion resembling low-density lipoprotein. Lipids 1993; 28: 691-696.

9. Yamamoto $M$, Ikeda K, Ohshima K, Tsugu H, Kimura $H$, Tomonaga M. Increased expression of low density lipoprotein receptor-related protein/alpha2-macroglobulin receptor in human malignant astrocytomas. Cancer Res 1997; 57: 2799-2805.

10. Strickland DK, Kounnas MZ, Argraves WS. LDL receptorrelated protein: a multiligand receptor for lipoprotein and proteinase catabolism. FASEB J 1995; 9: 890-898.

11. Herz J, Strickland DK. LRP: a multifunctional scavenger and signaling receptor. J Clin Invest 2001; 108: 779-784.

12. Brown MS, Herz J, Kowal RC, Goldstein JL. The low-density lipoprotein receptor-related protein: double agent or decoy? Curr Opin Lipid 1991; 2: 65-72.

13. Kowal RC, Herz J, Goldstein JL, Esser V, Brown MS. Low density lipoprotein receptor-related protein mediates uptake of cholesteryl esters derived from apoprotein E-enriched lipoproteins. Proc Natl Acad Sci U S A 1989; 86: 58105814.

14. Moestrup SK, Gliemann J, Pallesen G. Distribution of the alpha 2-macroglobulin receptor/low density lipoprotein receptor-related protein in human tissues. Cell Tissue Res 1992; 269: 375-382.

15. Henriksson P, Eriksson M, Ericsson S, Rudling M, Stege $\mathrm{R}$, Berglund $\mathrm{L}$, et al. Hypocholesterolaemia and increased elimination of low-density lipoproteins in metastatic cancer of the prostate. Lancet 1989; 2: 1178-1180.

16. Graziani SR, Igreja FA, Hegg R, Meneghetti C, Brandizzi LI, Barboza R, et al. Uptake of a cholesterol-rich emulsion by breast cancer. Gynecol Oncol 2002; 85: 493-497.

17. Pires LA, Hegg R, Valduga CJ, Graziani SR, Rodrigues DG, Maranhão RC. Use of cholesterol-rich nanoparticles that bind to lipoprotein receptors as a vehicle to paclitaxel in the treatment of breast cancer: pharmacokinetics, tumor uptake and a pilot clinical study. Cancer Chemother Pharmacol 2009; 63: 281-287.

18. Mendes S, Graziani SR, Vitorio TS, Padoveze AF, Hegg R, Bydlowski SP, et al. Uptake by breast carcinoma of a lipidic nanoemulsion after intralesional injection into the patients: a new strategy for neoadjuvant chemotherapy. Gynecol Oncol 2009; 112: 400-404.

19. Teixeira LC, Pinotti JA. Câncer da mama: Quimioterapia. In: Halbe HW (Editor), Tratado de Ginecologia. Vol. 3. São Paulo: Editora Roca; 2000. p 2019-2022.

20. Iwanik MJ, Shaw KV, Ledwith BJ, Yanovich S, Shaw JM. Preparation and interaction of a low-density lipoprotein:daunomycin complex with P388 leukemic cells. Cancer Res 1984; 44: 1206-1215

21. Masquelier M, Vitols S, Peterson C. Low-density lipoprotein as a carrier of antitumoral drugs: in vivo fate of drug-human low-density lipoprotein complexes in mice. Cancer Res 1986; 46: 3842-3847.

22. Maranhão RC, Graziani SR, Yamaguchi N, Melo RF, Latrilha MC, Rodrigues DG, et al. Association of carmustine with a lipid emulsion: in vitro, in vivo and preliminary studies in cancer patients. Cancer Chemother Pharmacol 2002; 49: 487-498.

23. Maranhão RC, Garicochea B, Silva EL, Dorlhiac-Llacer $P$,
Cadena SM, Coelho IJ, et al. Plasma kinetics and biodistribution of a lipid emulsion resembling low-density lipoprotein in patients with acute leukemia. Cancer Res 1994; 54: 46604666.

24. Oken MM, Creech RH, Tormey DC, Horton J, Davis TE, McFadden ET, et al. Toxicity and response criteria of the Eastern Cooperative Oncology Group. Am J Clin Oncol 1982; 5: 649-655.

25. American Joint Committee on Cancer (AJCC). AJCC Cancer Staging Manual. New York: Springer-Verlag; 2010.

26. Friedewald WT, Levy RI, Fredrickson DS. Estimation of the concentration of low-density lipoprotein cholesterol in plasma, without use of the preparative ultracentrifuge. Clin Chem 1972; 18: 499-502.

27. Ades A, Carvalho JP, Graziani SR, Amancio RF, Souen JS, Pinotti JA, et al. Uptake of a cholesterol-rich emulsion by neoplastic ovarian tissues. Gynecol Oncol 2001; 82: 84-87.

28. Azevedo $\mathrm{CH}$, Carvalho JP, Valduga CJ, Maranhão RC. Plasma kinetics and uptake by the tumor of a cholesterolrich microemulsion (LDE) associated to etoposide oleate in patients with ovarian carcinoma. Gynecol Oncol 2005; 97: 178-182.

29. De Vries TJ, Verheijen JH, de Bart AC, Weidle UH, Ruiter DJ, van Muijen GN. Decreased expression of both the low-density lipoprotein receptor-related protein/alpha(2)macroglobulin receptor and its receptor-associated protein in late stages of cutaneous melanocytic tumor progression. Cancer Res 1996; 56: 1432-1439.

30. Pinheiro KV, Hungria VT, Ficker ES, Valduga CJ, Mesquita $\mathrm{CH}$, Maranhão RC. Plasma kinetics of a cholesterol-rich microemulsion (LDE) in patients with Hodgkin's and nonHodgkin's lymphoma and a preliminary study on the toxicity of etoposide associated with LDE. Cancer Chemother Pharmacol 2006; 57: 624-630.

31. Dias ML, Carvalho JP, Rodrigues DG, Graziani SR, Maranhão RC. Pharmacokinetics and tumor uptake of a derivatized form of paclitaxel associated to a cholesterol-rich nanoemulsion (LDE) in patients with gynecologic cancers. Cancer Chemother Pharmacol 2007; 59: 105-111.

32. Teixeira RS, Valduga CJ, Benvenutti LA, Schreier S, Maranhão RC. Delivery of daunorubicin to cancer cells with decreased toxicity by association with a lipidic nanoemulsion that binds to LDL receptors. J Pharm Pharmacol 2008; 60: 1287-1295.

33. Lo Prete AC, Maria DA, Rodrigues DG, Valduga CJ, Ibanez OC, Maranhão RC. Evaluation in melanoma-bearing mice of an etoposide derivative associated to a cholesterol-rich nano-emulsion. J Pharm Pharmacol 2006; 58: 801-808.

34. Rodrigues DG, Maria DA, Fernandes DC, Valduga CJ, Couto RD, Ibanez OC, et al. Improvement of paclitaxel therapeutic index by derivatization and association to a cholesterol-rich microemulsion: in vitro and in vivo studies. Cancer Chemother Pharmacol 2005; 55: 565-576.

35. Teixeira RS, Curi R, Maranhão RC. Effects on Walker 256 tumour of carmustine associated with a cholesterol-rich microemulsion (LDE). J Pharm Pharmacol 2004; 56: 909914.

36. Hungria VT, Latrilha MC, Rodrigues DG, Bydlowski SP, Chiattone CS, Maranhão RC. Metabolism of a cholesterol-rich microemulsion (LDE) in patients with multiple myeloma and a preliminary clinical study of LDE as a drug vehicle for the treatment of the disease. Cancer Chemother Pharmacol 2004; 53: 51-60. 